\title{
Traumatic dental injuries among schoolchildren in Valencia, Spain
}

\author{
María Faus-Damiá ${ }^{1}$, Teresa Alegre-Domingo ${ }^{2}$, Ignacio Faus-Matoses ${ }^{3}$, Vicente Faus-Matoses ${ }^{4}$, Vicente-José \\ Faus-Llácer 5
}

\footnotetext{
${ }^{1}$ Qualified in Odontology. Diploma student of Oral Medicine and Surgery. Valencia University Medical and Dental School

${ }^{2}$ Qualified in Odontology. Collaborator Professor of Conservative Dentistry and Endodontics . Valencia University Medical and Dental School

${ }^{3}$ Licensed in Odontology. Currently studying a Master in Dental Prothesis. University Medical and Dental School

${ }^{4}$ Qualified in Odontology.Associate Professor of Conservative Dentistry and Endodontics. Valencia University Medical and Dental School

${ }^{5}$ Qualified in Medicine. Senior Professor of Conservative Dentistry and Endodontics. Director of the Master of Conservative Dentistry and Endodontics. Valencia University Medical and Dental School
}

Correspondence:

C/Berca 41

46680-Algemesi

Valencia (Spain)

fausuj@clinicafaus.com

Received: $13 / 03 / 2010$

Accepted: $31 / 05 / 2010$

Faus-Damiá M, Alegre-Domingo T, Faus-Matoses I, Faus-Matoses V, Faus-Llácer VJ. Traumatic dental injuries among schoolchildren in Valencia, Spain. Med Oral Patol Oral Cir Bucal. 2011 Mar 1;16 (2):e292-5. http://www.medicinaoral.com/medoralfree01/v16i2/medoralv16i2p292.pdf

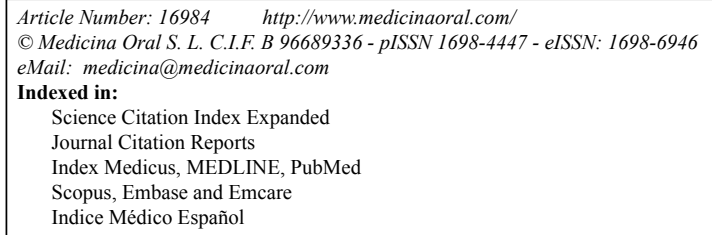

\begin{abstract}
Aim: The aim of the present study was to identify some factors related to the occurrence of dental trauma in mixed and permanent dentition.

Design of the study: Over a period of two months 1325, 6 to 18 year olds from three primary schools in Valencia were examined. Data was collected through clinical examinations and interviews and their Dental trauma was classified according to IADT's criteria. Results: The prevalence of dental injuries was $6 \%$; boys aged between 12-18 years old experienced more injuries than girls. There was a statistical difference between the types of fractures. Non complicated coronal fractures were the most frequent $(9.18 \%)$. Games were the main cause of trauma $(40 \%)$ in both sexes. In $14.3 \%$ of patients a dental colour change was observed. Angle's class I was the most frequent in traumatized injured children $(41.2 \%)$.

Conclusions: The present study revealed a relatively low prevalence of dental trauma, but this figure still represents a large number of children. Therefore, educational programs are to be initiated for the community regarding causes, prevention and treatments of traumatic dental injuries.
\end{abstract}

Key words: Dental injuries, traumatism and schoolchildren. 


\section{Introduction}

Dental trauma is a very significant problem in the primary dentition (1). Facial trauma can endanger dental health and lead to aesthetic, psychological, social and therapeutic problems (2).

Traumatic injuries in permanent teeth have been reported to have a prevalence rate between $6.1 \%$ to $58.6 \%$ (3-16). The great variation in reported rates can be attributed to a number of different factors, including types of study, trauma classification, methodology, study size and population, geographical location and differences in cultural behaviour (17).

The decline in the prevalence and severity of dental caries amongst children in many countries may have made traumatic dental injuries a more serious dental public health problem among the young. Dental trauma may exceed dental caries and periodontal disease as the most significant threat to dental health among young people $(17,18)$.

The aim of this study was to identify the prevalence of dental traumatism, age of occurrence, gender, type of injury, most affected teeth, clinical signs and symptoms, cause of trauma, in addition to angle's class and dental treatment needs in 3 public primary and secondary schools in Valencia.

\section{Materials and Methods}

The sample consisted of 1325 pupils (6-17 year olds) attending primary and secondary schools in Algemesí, Alzira and Valencia city, Spain. Permission and information regarding the number of pupils were obtained from the director of each school. The selected school authorities were conducted and the aim of the study was explained to ensure full cooperation.

All pupils were asked about if they have had suffered traumatism during their lives. Those who said yes were examined in classrooms to identify the type of traumatic injury. Students were examined seated, in a straight back chair under normal day light. The traumatic dental injuries were assessed according to IADT's criteria (18). Root fracture was not recorded as no radiographs were taken. Photographs from each pupil were also taken. Records were examined for the following: a) age at time of the injury ( $\leq 11$ years, $12-14$ years, $\geq 14$ years), b) sex, c) type of injury (non complicated fracture, complicated fracture, luxation, avulsion), d) type of teeth injured, e) clinical signs and symptoms crown discoloration, f) cause of injury, g) dental treatment needs (reconstruction, endodontics, extraction, re-implant), h) time from the accident to the dental office examination/ attendance. Occlusion was recorded according to Angle's classification. Data was subjected to a statistical analysis using the SPSS15.0 (SPSS Inc, Chicago, IL) software program for Windows. Chi-Square and Mann-Whitney tests were used to determine significant differences in data $(\mathrm{P}>0.05)$.

\section{Results}

The sample consisted of 1325 scholars, with an age range of $6-17$ years old, $51.2 \%$ males and $48.8 \%$ females (table 1), were distributed into three age groups (table 2 ). The prevalence of traumatized children was found to be $6.2 \%$. The highest prevalence of traumatized children was at the age of 12.2 years old (+/- 2.8). The most common type of dental injury was found to be non complicated coronal fracture (56\%), followed by luxation (4.9\%), complicated coronal fracture $(2.4 \%)$ and avulsion (1.2\%) (table 3).

The maxillary central incisors were found to be the most affected by dental trauma $(72.4 \%)$ in the same proportion of right and left ones, followed by maxillary lateral incisors $(10.2 \%)$ and lower central incisors $10.2 \%, 10.2 \%$ remaining includes different teeth from the previous ones and none repeated in more than two occasions. There was a significant relationship between trauma and the gender, being more common the injury in the upper central incisor among women (80\%) with regard to males $(p=0.01)$.

Table 1. Distribution of children with traumatized teeth according to sex.

\begin{tabular}{|c|c|c|}
\hline \multicolumn{1}{|c|}{ Age } & Males & Females \\
\hline 6-12 years old & 16 & 16 \\
\hline 12-18 years old & 27 & 23 \\
\hline$>18$ years old & 2 & 1 \\
\hline
\end{tabular}

Table 2. Distribution of children with traumatized teeth by age.

\begin{tabular}{|l|c|c|}
\hline & $\mathbf{N}$ & $\mathbf{\%}$ \\
\hline TOTAL & 82 & $100,0 \%$ \\
\hline Until 11 & 32 & $39,0 \%$ \\
\hline 12 to 14 & 32 & $39,0 \%$ \\
\hline Over 14 & 18 & $22,0 \%$ \\
\hline
\end{tabular}

Table 3. Distribution of the more common types of dental fracture.

\begin{tabular}{|l|l|l|}
\hline & \multicolumn{1}{|c|}{$\mathbf{N}$} & \multicolumn{1}{c|}{$\%$} \\
\hline TOTAL & 82 & $100,0 \%$ \\
\hline Non complicated & 46 & $56,1 \%$ \\
\hline Not assessable & 29 & $35,4 \%$ \\
\hline Luxation & 4 & $4,9 \%$ \\
\hline Complicated & 2 & $2,4 \%$ \\
\hline Avulsion & 1 & $1,2 \%$ \\
\hline
\end{tabular}


In $14.3 \%$ of individuals, discoloration of the teeth was present in the part affected, mainly yellowish hue.

The main reason for the trauma were accidents while practising sports $(40.2 \%)$, followed by falls (31.7\%),clenching (11\%), blow (8.5\%), traffic accident $(2.4 \%)$, and $6.1 \%$ remaining did not remember.

The most common treatment done was dental fillings $(43.2 \%)$, followed by endodontics $(4.9 \%)$, extraction (2.5\%), re- implant (2.5\%) and $37 \%$ were never treated. Time to visit the dentist since the traumatism occurred was variant; a large majority came before the first week (53\%), while $34 \%$ was not treated before.

Traumatized children with class I were more common (39\%) than with other type of occlusion, followed by combinations of class II (division I and II), class II maloclussion (17.1\%) and finally, 9.8\% with class III.

\section{Discussion}

In this study the age at when the traumatism were more frequent was 8.6 years old, which is in agreement with other studies $(3,5)$ and lower than other studies $(7,8,9)$. Males were more affected by dental trauma $(51.2 \%)$ than females $(48.8 \%)$.This result was in agreement with many studies $(2,4,5,8,9,14)$ and this may be due to the fact males tend to participate in more strenuous activities with higher trauma risk, such as contact sports and more aggressive types of playing.

Provided that no other variable was related to the sex, the explanation to the fact of which the males have a major variety of affected teeth might be in the higher intensity of the impact or a variety of possible positions of the face at the moment of impact.

The prevalence of dental trauma in the present study was recorded to be $6.19 \%$, been higher than those recorded by Al Kassab (11) and Rai and Munshi (12), but lower than those findings reported by some other investigators $(4,7,9)$. As been as shown in other studies, non complicated coronal fracture was the most common type of dental injury (3-5,7-10).

Maxillary central upper incisors were the most common teeth affected by dental trauma. This result agrees with most previous studies regarding the maxillary central incisors are the most common teeth to receive trauma (3-6, 8-10, 14). The prominent and vulnerable position of the maxillary incisors in the face is responsible for their more frequent involvement in fractures than the lower teeth (15).

The most frequent injury setting was falling while playing sports or games which is in agreement with the study recorded by Soriano E.P (4) and similar to other studies $(2,3,5)$.

In conclusion, the present study revealed a relatively low prevalence of dental trauma, but still this figure represents a large number of children.

In this study $14.3 \%$ of individuals, presented discolora- tion of the teeth affected, this results are higher from that found by Altun et al (3).

The most common treatment done was dental fillings $(43.2 \%)$, and $37 \%$ were never treated; This result may be explained by the fact that the major types of trauma were non complicated coronal fractures, which is in agreement with the results found by Noori and AlObaidi (2).

Traumatized children with class I were more common (39\%) than with other type of occlusion; whereas in other studies injuries were found to occur more frequently in class II $(2,10)$.

Prevention of dental injury is considered to be more important from every aspect of the problem than its treatment similar to other general and oral health problems. Therefore educational programs are to be initiated for the community regarding causes, prevention and treatments of traumatic dental injuries.

\section{References}

References with links to Crossref - DOI

1. Flores MT. Traumatic injuries in the primary dentition. Dent Traumatol. 2002;18:287-98.

2. Noori AJ, Al-Obaidi WA. Traumatic dental injuries among primary school children in Sulaimani city, Iraq. Dent Traumatol. 2009;25:442-6.

3. Altun C, Ozen B, Esenlik E, Guven G, Gürbüz T, Acikel C, et al. Traumatic injuries to permanent teeth in Turkish children, Ankara. Dent Traumatol. 2009;25:309-13.

4. Soriano EP, Caldas Ade F Jr, Diniz De Carvalho MV, Amorim Filho Hde A. Prevalence and risk factors related to traumatic dental injuries in Brazilian schoolchildren. Dent Traumatol. 2007;23:232-40.

5. Kargul B, Cağlar E, Tanboga I. Dental trauma in Turkish children, Istanbul. Dent Traumatol. 2003;19:72-5.

6. David J, Astrøm AN, Wang NJ. Factors associated with traumatic dental injuries among 12-year-old schoolchildren in South India. Dent Traumatol. 2009;25:500-5.

7. Bauss O, Röhling J, Schwestka-Polly R. Prevalence of traumatic injuries to the permanent incisors in candidates for orthodontic treatment. Dent Traumatol. 2004;20:61-6.

8. Ivancic Jokic N, Bakarcic D, Fugosic V, Majstorovic M, Skrinjaric I. Dental trauma in children and young adults visiting a University Dental Clinic. Dent Traumatol. 2009;25:84-7.

9. Zaragoza AA, Catalá M, Colmena ML, Valdemoro C. Dental trauma in schoolchildren six to twelve years of age. ASDC J Dent Child. 1998;65:492-4, 439.

10. Navabazam A, Farahani SS. Prevalence of traumatic injuries to maxillary permanent teeth in 9- to 14-year-old school children in Yazd, Iran. Dent Traumatol. 2010;26:154-7.

11. Rai SB, Munshi AK. Traumatic injuries to the anterior teeth among South Kanara school children--a prevalence study. J Indian Soc Pedod Prev Dent. 1998;16:44-51.

12. Garcia-Godoy F, Morbán-Laucer F, Corominas LR, Franjul RA, Noyola M. Traumatic dental injuries in schoolchildren from Santo Domingo. Community Dent Oral Epidemiol. 1985;13:177-9.

13. Jesus MA, Antunes LA, Risso Pde A, Freire MV, Maia LC. Epidemiologic survey of traumatic dental injuries in children seen at the Federal University of Rio de Janeiro, Brazil. Braz Oral Res. 2010;24:89-94.

14. Falomo B. Fractured permanent incisors among Nigerian school children. ASDC J Dent Child. 1986;53:119-21.

15. Canakci V, Akgül HM, Akgül N, Canakci CF. Prevalence and handedness correlates of traumatic injuries to the permanent incisors in 13-17-year-old adolescents in Erzurum, Turkey. Dent Traumatol. 2003; $19: 248-54$. 
16. Altay N, Güngör HC. A retrospective study of dento-alveolar injuries of children in Ankara, Turkey. Dent Traumatol. 2001;17:201-4.

17. Petersson GH, Bratthall D. The caries decline: a review of reviews. Eur J Oral Sci. 1996;104:436-43.

18. Flores MT, Andersson L, Andreasen JO, Bakland LK, Malmgren B, Barnett F, et al. Guidelines for the management of traumatic dental injuries. I. Fractures and luxations of permanent teeth. Dent Traumatol. 2007;23:66-71. 